\title{
Experimental investigation on ultimate strength and failure response of composite box beams used in wind turbine blades
}

\author{
Tang, Jing; Chen, Xiao
}

\section{Published in:}

Composite Structures

Link to article, DOI:

10.1016/j.compstruct.2018.05.042

Publication date:

2018

Document Version

Peer reviewed version

Link back to DTU Orbit

\section{Citation (APA):}

Tang, J., \& Chen, X. (2018). Experimental investigation on ultimate strength and failure response of composite box beams used in wind turbine blades. Composite Structures, 198, 19-34.

https://doi.org/10.1016/j.compstruct.2018.05.042

\section{General rights}

Copyright and moral rights for the publications made accessible in the public portal are retained by the authors and/or other copyright owners and it is a condition of accessing publications that users recognise and abide by the legal requirements associated with these rights.

- Users may download and print one copy of any publication from the public portal for the purpose of private study or research.

- You may not further distribute the material or use it for any profit-making activity or commercial gain

- You may freely distribute the URL identifying the publication in the public portal

If you believe that this document breaches copyright please contact us providing details, and we will remove access to the work immediately and investigate your claim 


\section{Accepted Manuscript}

Experimental investigation on ultimate strength and failure response of composite box beams used in wind turbine blades

Jing Tang, Xiao Chen

PII: S0263-8223(18)30421-5

DOI: https://doi.org/10.1016/j.compstruct.2018.05.042

Reference: COST 9681

To appear in:

\section{Composite Structures}

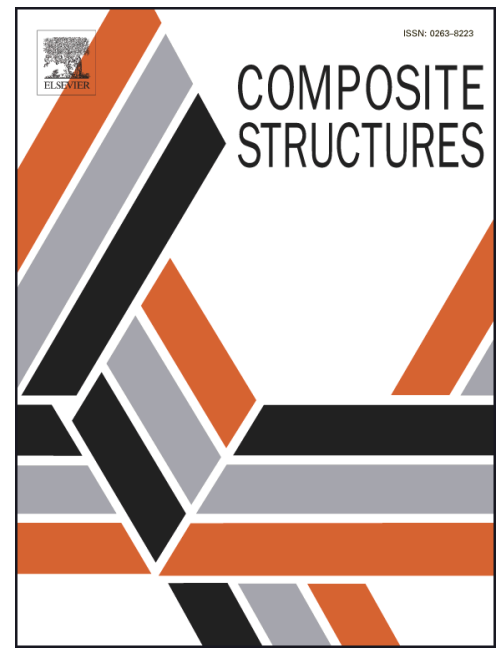

Received Date: 27 January 2018

Revised Date: $\quad 8$ April 2018

Accepted Date: $\quad 8$ May 2018

Please cite this article as: Tang, J., Chen, X., Experimental investigation on ultimate strength and failure response of composite box beams used in wind turbine blades, Composite Structures (2018), doi: https://doi.org/10.1016/ j.compstruct.2018.05.042

This is a PDF file of an unedited manuscript that has been accepted for publication. As a service to our customers we are providing this early version of the manuscript. The manuscript will undergo copyediting, typesetting, and review of the resulting proof before it is published in its final form. Please note that during the production process errors may be discovered which could affect the content, and all legal disclaimers that apply to the journal pertain. 


\title{
Experimental investigation on ultimate strength and failure response of composite box beams used in wind turbine blades
}

\author{
Jing Tang \# a,b,c , Xiao Chen \# d,* \\ ${ }^{a}$ Key Laboratory of Wind Energy Utilization, Institute of Engineering Thermophysics, Chinese Academy of Sciences, Beijing 100190, \\ China \\ ${ }^{\mathrm{b}}$ University of Chinese Academy of Sciences, Beijing, 100190, China \\ ${ }^{c}$ National Laboratory of Wind Turbine Blade Research \& Development Center, Beijing, 100190, China \\ ${ }^{d}$ Department of Wind Energy, Technical University of Denmark, Frederiksborgvei 399, 4000 Roskilde, Denmark \\ \# Both authors contributed equally to this work. Contribution details are included in the author contributions section
}

\begin{abstract}
This study focuses on the ultimate strength and failure response of composite box beams under three-point bending. The box beams consist of spar caps and shear webs and they are typically used in wind turbine blades as load-carrying members. Different spar cap configurations and loading directions are examined experimentally to investigate structural behavior associated with multiple nonlinearities leading to structural collapse. Global displacements, local strains and video images are recorded throughout the loading history to capture failure initiation, propagation and the strain state contributing to post-collapse characteristics. The failure mechanisms of the box beams involving geometric, material and contact nonlinearities are discussed in detail. The study shows that compressive crushing failure, driven by local buckling of shear webs, determines the ultimate strength of the box beams under flapwise loading, and adhesive joint debonding, initiated by local adhesive cracking and spar cap buckling, is the critical failure mode of the box beams under edgewise loading. The Brazier effect and shear nonlinearity contribute to the initial failure depending on the loading directions. Debonding rather than delamination characterizes post-collapse behavior of all box beams examined in this study.
\end{abstract}

\section{Keywords:}

nonlinearity; failure mode, composite; delamination; buckling; debonding; collapse

\section{Introduction}

A wind turbine blade is a hollow composite structure with outer aerodynamic shells and an internal loading-carrying member. Typically, the loading-carrying member is designed with a box-shaped cross section and usually consists of spar caps and shear webs adhesively bonded together. Experimental determination of ultimate strength of rotor blades is usually conducted through full-scale structural collapse tests, which provide invaluable information on failure mechanisms enabling further optimization of structural design [1-6]. Nevertheless, there are limitations of structural collapse tests of full-scale blades. First of all, technical, safety, and cost risks of these tests have increased dramatically with the growth of blade sizes in recent years, it is physically and economically challenging to load a very large full-scale blade to complete collapse as addressed by Chen [6]. Second, it should be noted that different structural designs with different blade geometries, material properties, load combinations, etc., lead to significant difference in structural behavior. The failure mechanism derived from one particular blade may not be necessarily applicable to other blades. One solution to deal with these limitations is through multi-scale testing, see Fig. 1(a), in which a test pyramid consisting of coupon testing, component testing and full-scale structural testing is used to evaluate structural performance of wind turbine blades at different scales as proposed by the DNV GL standard [7].

Typical failure modes of composite blades were studied in the full-scale collapse tests [1-6, 8-12], including geometric nonlinearity mainly characterized as local buckling and cross-sectional ovalization, i.e., the Brazier effect, and material failures such as fiber breakage, matrix damage, debonding and delamination. These failure modes and failure behavior have also been investigated in more general thin-walled composite structures [13-15]. Nevertheless, the failure response has not been adequately studied in load-carrying 
box beam components, despite their critical role in determining structural strength and failure of wind turbine blades. So far, a few studies have considered the composite box beams used in wind turbine blades. Cole et al. [16] and Yu et al. [17] studied composite box beams to emulate structural characteristics of a rotor blade under flapwise loading in three-point and four-point bending tests. Their work focused on the failure modes and ultimate strength of the box beams and concluded that the adhesive layer had an appreciable impact on the load-carrying capability. Although the failure modes were presented and discussed, the root cause and interactive nonlinear behavior can be further explored in order to better understand the underlying failure mechanisms.

Fig. 1 Multi-scale structural testing of wind turbine blades

The composite box beam, as a backbone of the rotor blade, can be considered as a generic model for accessing structural strength and failure both experimentally and numerically at the component level. The entire planned work, as shown in Fig. 1(b), cannot be performed in a single study, and this paper is only the first step toward understanding how multiple local nonlinearities affect the global structural response including the final collapse. The scope of the current work is limited to experimental investigation of strength and failure of load-carrying box beams with rectangular cross sections. A particular focus is placed on interactive nonlinear structural behavior leading to the final structural collapse.

A simple three-point bending test setup is used in this study. Both flapwise and edgewise loading, which are required for certifying a new type of rotor blades in full-scale [18], are applied to the box beams. In the flapwise loading, pre-delamination is introduced in the spar caps as delamination is reported as a critical failure mode directly responsible for the loss of the load-carrying capacity of the blade and determining the ultimate load-carrying capacity [6]. With these tests, this study tries to achieve specific purposes as follows:

○ understand failure mechanisms associated with failure initiation, propagation and the strain state of composite box beams used in wind turbine blades;

- examine different failure modes, ultimate strength and failure response between the flapwise loading and the edgewise loading;

- analyze the influence of pre-delamination on the load-carrying capacity and post-collapse characteristics.

The following section introduces design and manufacturing of the box beam components and the test method; section 3 analyzes the pre-peak structural response; section 4 provides a detailed description of the failure response considering multiple nonlinear phenomena; and finally, section 5 addresses the plausible failure mechanism of the box beams.

\section{Box beam components and test method}

\subsection{Component design}

The composite box beams are designed with reference to typical materials used in a generic load-carrying member in wind turbine blades. A region of blade length ranging from $30 \%$ to $45 \%$, which is critical to structural integrity under extreme wind conditions [1921], is considered for designing cross sections of the box beams. A schematic description of the box beams is shown in Fig. 2.

Fig. 2 Geometry of box beams

A total of five box beams are manufactured, and their component design and loading scheme are presented in Table 1. CB_F2 and CB_E2 have the same materials and geometries; and CB_F1 and CB_E1 have thinner spar caps with 2 unidirectional plies. CB_F3 is designed with pre-delamination in the intermediate layers of spar caps by sandwiching a thin film of Teflon. The corresponding measured dimensions are listed in Table 2. 
Table 1 Component design and loading scheme of box beams

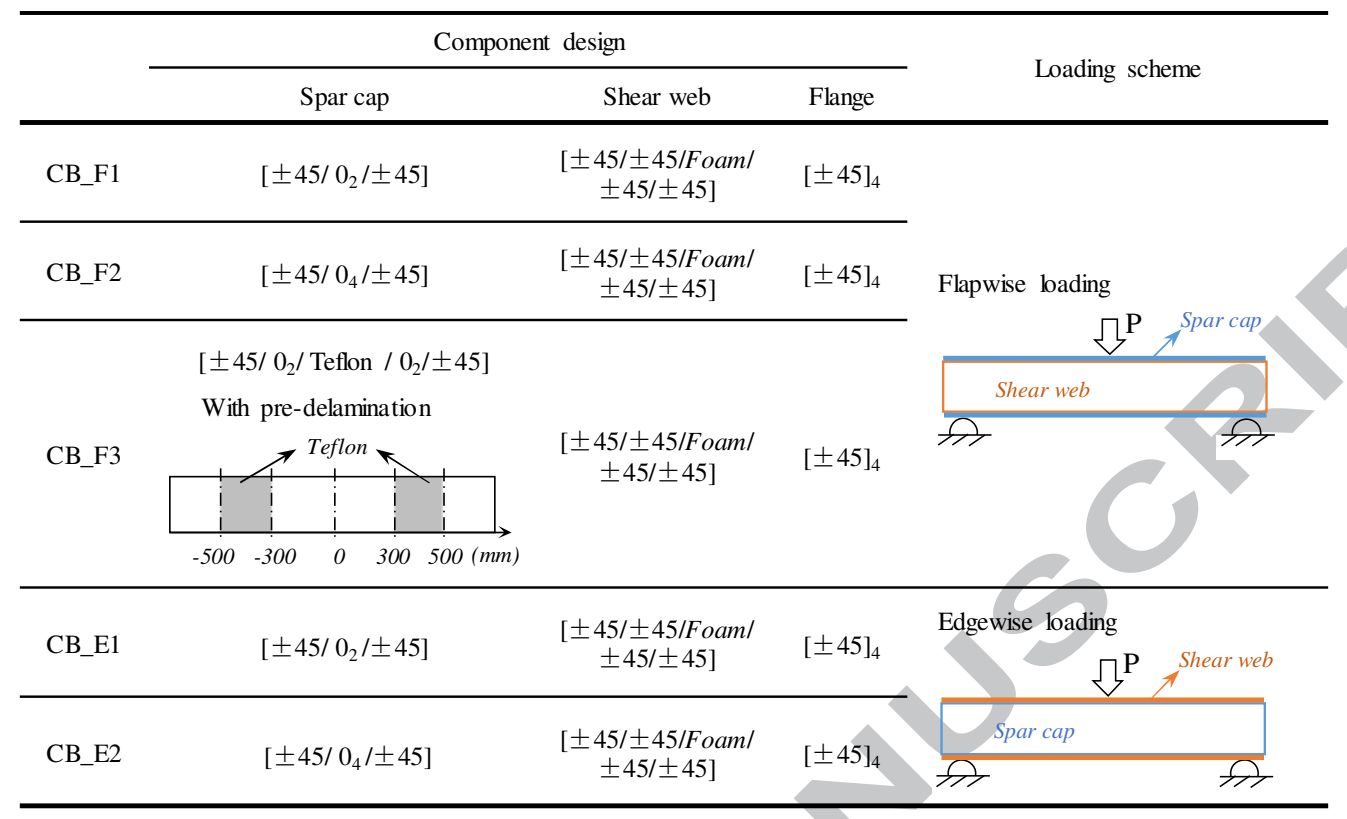

Table 2 Measured dimensions of box beams ( $\mathrm{mm})$

\begin{tabular}{cccccccccc}
\hline & $\begin{array}{c}\text { Beam } \\
\text { length } \\
L_{B}\end{array}$ & $\begin{array}{c}\text { Beam } \\
\text { height } \\
H\end{array}$ & $\begin{array}{c}\text { Beam } \\
\text { width } \\
W\end{array}$ & $\begin{array}{c}\text { Spar cap } \\
\text { thickness }\end{array}$ & $\begin{array}{c}\text { Shear web } \\
\text { thickness }\end{array}$ & $\begin{array}{c}\text { Flange } \\
\text { width }\end{array}$ & $\begin{array}{c}\text { Flange } \\
\text { thickness } \\
t_{S W}\end{array}$ & $\begin{array}{c}\text { Adhesive } \\
\text { thickness }\end{array}$ & $\begin{array}{c}\text { Support } \\
\text { span } \\
t_{F L}\end{array}$ \\
\hline CB_F1 & 1813.3 & 257.9 & 239.9 & 3.53 & 13.72 & 34.52 & 3.40 & 3.05 & 1606.0 \\
CB_F2 & 1819.0 & 260.4 & 240.4 & 5.26 & 13.48 & 33.70 & 3.40 & 2.91 & 1606.0 \\
CB_F3 & 1819.7 & 264.3 & 240.0 & 5.34 & 13.79 & 34.48 & 3.40 & 3.20 & 1606.0 \\
CB_E1 & 1810.0 & 257.4 & 240.3 & 3.42 & 13.62 & 33.11 & 3.40 & 3.53 & 1603.0 \\
CB_E2 & 1815.0 & 260.3 & 240.4 & 5.06 & 13.33 & 33.54 & 3.40 & 3.11 & 1603.0 \\
\hline
\end{tabular}

\subsection{Component manufacturing}

The box beams are made of glass/epoxy composite, PVC foam and epoxy-based adhesive. Their elastic constants, strength properties and designed thickness are listed in Table 3, where the superscript $u$ presents ultimate state and the subscripts $t$ and $c$ present tension and compression, respectively. The spar cap is a composite laminate consisted of unidirectional and biaxial plies. The shear web is a sandwich panel with biaxial plies in facesheets and PVC foam in the core. Flanges consisting of 4 biaxial plies are used in shear webs as bond surfaces. During the manufacturing, four parts, i.e., two spar caps and two shear webs, were first manufactured using a resin vacuum infusion manufacturing process. Next, the parts were symmetrically assembled as an integrated box structure bonded by an adhesive layer. This manufacturing process is shown in Fig. 3. The curing schedule followed the same factory production as that of commercial blades. All box beams were cured at $60^{\circ} \mathrm{C}$ for 5 hours right after manufacturing using heating pads and then next day they were moved to a heating chamber to post cure at $70^{\circ} \mathrm{C}$ for 4 hours.

Table 3 Elastic constants, strength properties and designed thickness of materials used in box beams

\begin{tabular}{|c|c|c|c|c|c|c|c|c|c|c|}
\hline \multirow[b]{2}{*}{ Materials } & \multicolumn{4}{|c|}{ Elastic constants } & \multicolumn{5}{|c|}{ Strength properties } & \multirow{2}{*}{$\begin{array}{c}\text { Designed } \\
\text { thickness } \\
(\mathrm{mm})\end{array}$} \\
\hline & $\begin{array}{c}E_{11} \\
(\mathrm{GPa}) \\
\end{array}$ & $\begin{array}{c}E_{22} \\
(\mathrm{GPa}) \\
\end{array}$ & $\begin{array}{c}G_{12} \\
(\mathrm{GPa}) \\
\end{array}$ & $\begin{array}{c}\mu_{12} \\
(-) \\
\end{array}$ & $\begin{array}{c}\sigma_{11 t}^{u} \\
(\mathrm{MPa})\end{array}$ & $\begin{array}{c}\sigma_{11 c}^{u} \\
(\mathrm{MPa}) \\
\end{array}$ & $\begin{array}{c}\sigma_{22 t}^{u} \\
(\mathrm{MPa})\end{array}$ & $\begin{array}{c}\sigma_{22 c}^{u} \\
(\mathrm{MPa})\end{array}$ & $\begin{array}{c}\sigma_{12}^{u} \\
(\mathrm{MPa})\end{array}$ & \\
\hline Unidirectional ply & 39.0 & 13.0 & 3.4 & 0.205 & 850 & 500 & 38 & 170 & 50 & 0.90 \\
\hline Biaxial ply & 12.5 & 12.5 & 10.3 & 0.498 & 160 & 160 & 160 & 160 & 241 & 0.85 \\
\hline PVC Foam & 0.035 & 0.035 & 0.022 & 0.300 & 1.2 & 0.6 & 1.2 & 0.6 & 0.76 & 10.00 \\
\hline
\end{tabular}


Fig. 3 Manufacturing of the box beam CB_F1

\subsection{Experimental setup}

The test setup of three-point bending is shown in Fig. 4. Displacement-controlled static load is applied to the loading plate on the top of mid-span section of the box beam. This applied load is recorded by the load cell mounted on the hydraulic actuator during the loading process. A simple supported boundary is applied to both ends of the box beam using two arc supports. Two composite plates are adhesively bonded to the box beam at the supported ends to avoid local failure. Two displacement sensors are arranged at both left and right sides of the bottom surface of the box beam to measure mid-span deflections.

Fig. 4 Experimental setup of box beam testing

As the collapse process is drastic and lasts only a short period of time, a data acquisition system with high frequency of $100 \mathrm{~Hz}$ is used to record the load, displacement and strain response. Fig. 5 shows the deployment of strain gauges in the regions of most concern. Six cameras are placed in different locations to capture failure response of box beams during the tests. Grids are drawn on the outside surfaces of box beams to better visualize local deformation.

Fig. 5 Deployment of strain gauges on the box beams

\section{Pre-peak structural response}

\subsection{Load-displacement response}

The plots of the applied static load versus the mid-span deflection of the five box beams are shown in Fig. 6. The solid line and dashed line of the response curves represent different displacements collected from the right and left sides of the box beam, respectively.

Fig. 6 Load-displacement response of five box beams under three-point bending

The two horizontal lines in each figure indicate the ultimate load level and the residual load level of the box beam and they are marked as $P^{U}$ and $P^{R}$, respectively. The ultimate loads under edgewise loading are larger than those under flapwise loading of the same structure, whereas the opposite trend is observed for residual loads. The slopes of the elastic response can be viewed as the linear tangential bending stiffness of the box beams under three-point bending and they are summarized in Table 4 . A difference in the bending stiffness is observed between the left side and the right side. The main reason for this difference is possibly due to asymmetric distribution of geometric sizes of box beams and load introduction. The elastic properties of each component are calculated in Table 5 for CB_F2 and CB_F3 as representatives. The differences in these properties between the two box beams explain the observation that the ultimate load of CB_F3 with a pre-delamination defect is higher than that of CB_F2 without the defect. 
Table 4 Comparison of ultimate loads, residual loads and linear tangential stiffness of box beams

\begin{tabular}{|c|c|c|c|c|c|c|}
\hline & \multirow{2}{*}{$\begin{array}{c}\text { Ultimate load (kN) } \\
P_{E x p .}^{U} \\
\end{array}$} & \multirow{2}{*}{$\begin{array}{c}\text { Residual load (kN) } \\
P_{E x p .}^{R} \\
\end{array}$} & \multicolumn{3}{|c|}{ Linear tangential stiffness $(\mathrm{kN} / \mathrm{mm})$} & \multirow{2}{*}{$\begin{array}{c}\text { Average stiffness } \\
\text { difference } \\
(\%) \\
\end{array}$} \\
\hline & & & $k_{\text {Exp. }}^{R}$ & $k_{E x p}^{L}{ }^{*}$ & $k_{E q .(6)}$ & \\
\hline CB_F1 & 37.16 & 18.00 & 7.68 & 8.85 & 7.84 & -5.14 \\
\hline CB_F2 & 43.30 & 18.60 & 9.06 & 10.20 & 11.53 & 19.73 \\
\hline CB_F3 & 50.20 & 19.50 & 12.22 & 9.00 & 12.04 & 13.48 \\
\hline CB_E1 & 49.98 & 13.00 & 5.47 & 5.39 & 4.79 & -11.79 \\
\hline CB_E2 & 87.60 & 13.50 & 7.42 & 6.76 & 6.27 & -11.57 \\
\hline
\end{tabular}

* The experimental stiffness (at right and left sides) calculated from relatively linear segment of the load-displacement curve:

$40 \sim 80 \% P_{E x p}^{U}$. for beams under flapwise loading and 60 80\% $P_{E x p}^{U}$. for beams under edgewise loading.

Table 5 Comparison of component thickness and equivalent engineering elastic properties between CB_F2 and CB_F3

\begin{tabular}{|c|c|c|c|c|c|c|c|c|}
\hline & \multicolumn{3}{|c|}{ CB_F2 } & \multicolumn{3}{|c|}{ CB_F3 } & \multirow[b]{2}{*}{$(E I)_{2} /(E I)_{1}$} & \multirow[b]{2}{*}{$(G A)_{2} /(G A)$} \\
\hline & $\begin{array}{c}\text { Thickness } \\
(\mathrm{mm})\end{array}$ & $\begin{array}{c}(E I)_{1} \\
\left(\mathrm{kN} \cdot \mathrm{mm}^{2} \times 10^{6}\right)\end{array}$ & $\begin{array}{l}(G A)_{1} \\
(\mathrm{kN})\end{array}$ & $\begin{array}{c}\text { Thickness } \\
\text { (mm) }\end{array}$ & $\begin{array}{c}(E I)_{2} \\
\left(\mathrm{kN} \cdot \mathrm{mm}^{2} \times 10^{6}\right)\end{array}$ & $\begin{array}{l}(G A)_{2} \\
(\mathrm{kN})\end{array}$ & & \\
\hline Top spar cap & 5.30 & 638 & -- & 5.38 & 666 & -- & \multirow{2}{*}{1.044} & \multirow{2}{*}{--} \\
\hline Bottom spar cap & 5.22 & 629 & -- & 5.30 & 657 & -- & & \\
\hline Right shear web & 13.34 & 49 & 8424 & 13.82 & 54 & 8863 & \multirow{2}{*}{1.072} & \multirow{2}{*}{1.039} \\
\hline Left shear web & 13.62 & 51 & 8601 & 13.78 & 53 & 8831 & & \\
\hline Total & -- & 1367 & 17025 & -- & 1430 & 17694 & 1.046 & 1.039 \\
\hline
\end{tabular}

\subsection{Shear nonlinearity}

Unidirectional fiber composites exhibit considerable nonlinearity under in-plane shear. The nonlinear shear modulus of the unidirectional layer was proposed by Chang and Lessard [22]:

$$
\bar{G}_{12}=\frac{1}{G_{12}^{-1}+3 \alpha \sigma_{12}^{2}}
$$

where $G_{12}$ is the initial in-plane shear modulus. The shear nonlinearity is characterized by the factor $\alpha$, which can be determined from material tests. Note that $\bar{G}_{12}$ depends on the current value of the shear stress, and $\bar{G}_{12}=G_{12}$ when $\alpha=0$.

Interestingly, as shown in Figs. 6(d) and (e), the load-displacement curves under edgewise loading show softening nonlinear characteristics at the pre-peak stage, which are quite different from the observation found in the flapwise cases. When the box beams are loaded in an edgewise direction, the spar caps with unidirectional plies are mainly subject to in-plane shear force and thus exhibit shear nonlinearity, which in turn is reflected by nonlinearity of the global load-displacement response. This shear nonlinearity would affect load transfer between shear webs and spar caps. Local material damage may initiate and change the failure process of the box beams, which will be discussed in the following sections.

\subsection{Stiffness calculation}

In order to predict bending stiffness of the box beams under three-point bending, this study simplifies composite box beams as sandwich beams with low stiffness core (shear webs) between two thin facesheets, i.e., spar caps. The total deflection at the mid-point of a simply supported sandwich beam loaded in three-point bending has been studied by [23-24], and the relation can be determined by the following:

$$
\delta_{\text {sandwich }}=\frac{P L^{3}}{48(E I)_{e q}}+\frac{P L}{4(G A)_{e q}}
$$




$$
\begin{aligned}
& (E I)_{e q}=\frac{E_{f} b t_{f} d^{2}}{2}+\frac{E_{f} b t_{f}^{3}}{6}+\frac{E_{c} b t_{c}^{3}}{12} \\
& (G A)_{e q}=\frac{b d^{2} G_{c}}{c}
\end{aligned}
$$

where $P$ is the applied concentrated load; $L$ is the beam length; $b$ is the beam width; $t$ is the beam thickness; the subscripts $f$ and $c$ represent the facesheet and core, respectively; and $d=t_{f}+t_{c}$ is the distance between the centroids of the facesheets. In Eq. (2), the first term is the bending deflection of the beam, and the second term is the shear deflection, where $(E I)_{e q}$ is the equivalent flexural rigidity and $(G A)_{e q}$ is the equivalent shear rigidity. For the box beam under flapwise loading in this study, Eq. (2) can be modified to Eq. (5):

$$
\delta_{C B F} \approx \frac{P L^{3}}{48\left((E I)_{s c}+(E I)_{s w}\right)}+\frac{P L}{4(G A)_{s w}}
$$

where the subscripts $s c$ and $s w$ denote the spar cap and shear web, respectively. In this equation, the thick adhesive layer of the box beam is negligible because of its relatively small modulus. For a composite box beam under three-point bending in the flapwise direction, the bending stiffness is estimated as:

$$
k_{C B F}=\frac{P}{\delta_{C B F}} \approx \frac{1}{\frac{L^{3}}{48\left((E I)_{s c}+(E I)_{s w}\right)}+\frac{L}{4(G A)_{s w}}}
$$

With nonlinear shear rigidity of the spar caps $(\bar{G} A)_{s c}$ taken into consideration, the bending stiffness under edgewise loading is estimated as:

$$
k_{C B E}=\frac{P}{\delta_{C B E}} \approx \frac{1}{\frac{L^{3}}{48\left((E I)_{s c}+(E I)_{s w}\right)}+\frac{L}{4(\bar{G} A)_{s c}}}
$$

where $(\bar{G} A)_{s c}=(G A)_{s c}$ when $\alpha=0$. Table 4 shows a comparison of the linear stiffness as determined by the relatively linear segment of experimental load-displacement curve and by calculation using Eq. (6-1) and Eq. (6-2) with $\alpha=0$. This calculation provides slightly higher stiffness values than the experiment under flapwise loading. For the edgewise loading, the stiffness prediction is off possibly due to the shear nonlinearity which is not considered in the calculation.

\section{Failure response}

Four aspects of failure response are discussed to understand nonlinear behavior of the box beams. They are the load-displacement response, local strains, progressive chain of events and post-collapse characteristics.

\subsection{Collapse process and failure modes}

\subsubsection{Flapwise loading}

The load-carrying capacity shows a progressive drop after ultimate strength. The collapse process is divided into several stages for discussion, as shown in the first column of Fig. 7, where ' $P_{1}, P_{2}, P_{3}, P_{4}, P_{5}$ ' are marked with dots to highlight current load levels. Failure events and the load levels are correlated as shown in Fig. 7 for the failure process of the box beam CB_F2. The same procedure is implemented for CB_F3, and the failure response corresponding to the load levels ' $P_{a}, P_{b}, P_{c}, P_{d}, P_{e}$ ' is shown in Fig. 8.

Fig. 7 Failure response of CB_F2 as loading history

Fig. 8 Failure response of CB_F3 as loading history

\section{- Local buckling leading to material failure}

Local buckling of shear webs in the form of bulging is observed before the box beams reach the ultimate load, as shown in Fig. 7(b) and Fig. 8(b). In the CB_F2 test, nonlinear relationship between the applied load and the mid-span displacement of the box beam starts from $P_{C F B 2}^{N L}=39.19 \mathrm{kN}$ due to shear web buckling. In the CB_F3 test, the buckling phenomenon is recorded by transverse strains along the height of the mid-span section, as shown in Fig. 8(b-iii), which reveals that considerable nonlinearity occurs just before the shear 
web is about to fail. This figure also shows that the absolute value of strain at location \#2 eventually decreases to zero, suggesting local material failure as a result of severe local buckling.

\section{- Interaction between spar caps and shear webs}

Fig. 8(b) reveals a concave transverse deformation of the top spar cap at the mid-span section. This transverse deformation is possibly driven by the Brazier effect for beams with a hollow cross section under bending. As spar caps and shear webs are adhesively bonded together, adhesive joints connecting these two parts transfer forces as well as serve as edge constraints. When the top spar cap deforms transversely, the buckling of the adjacent shear webs would be facilitated, which in turn leads to further deformation of the spar cap. In this sense, the local buckling of the shear web is affected not only by compression force due to the global bending of the box beam but also by cross sectional deformation of spar caps.

\section{- Crushing failure at the ultimate state}

The local buckling in shear webs drives the box beam to its ultimate strength, when a significant drop in load-carrying capacity occurs. Local buckling as well as the applied load lead to local compressive crushing failure of the shear web adjacent to the top spar cap. The shear web at the side with weak bending stiffness collapses first, consistent with the two different slopes in the loaddisplacement graph. Fig. 7(c-ii) and Fig. 8(c-ii) provide clear images of the crushing failure of the shear web together with the tilt of the loading plate. The whitening region underneath the loading plate indicates material damage. As the crushing region is quite close to the bonding region, adhesive cracking in the vicinity of the loading plate also occurs as can be found in the post-collapse observation.

- Post-peak response associated with debonding and delamination

The failure modes during the post-peak stage are similar between CB_F2 and CB_F3. On the side without shear web crushing, a pair of oblique cracks develops symmetrically near the $120 \mathrm{~mm}$ position at the adhesive joint, as shown in Fig. 7(c-iii) and Fig. 8(d-ii). As the increase of displacement, a similar shear web crushing failure occurs as shown in Fig. 7(d) and Fig. 8(e). At this time of event, the existing adhesive cracks propagate from $120 \mathrm{~mm}$ to the far end away from the loading point along the longitudinal direction of the box beams, as recorded in Fig. 7(d-ii) and Fig. 8(e-ii), leading to separation between the top spar cap and the shear web. During this process, the Teflon film separates from unidirectional ply but this pre-delamination does not propagate as shown in Fig. 7(e-ii). The bottom spar caps in both box beams are still intact, and their structural integrity leads to similar residual loads for both box beams.

\subsubsection{Edgewise loading}

The load-displacement curves of CB_E1 and CB_E2 under edgewise loading are shown in Fig. 9(a). The curves exhibit three distinct events with load fluctuations as marked as 'I, II, and III'. Images captured from cameras are selected to demonstrate the relevant failure events, as shown in Figs. 9 (b) and (c).

Fig. 9 Failure response of box beams under edgewise loading

\section{- Spar cap bulging and material failure before the ultimate state}

Bulging out of the spar cap is observed in event ' $\mathrm{I}$ ', and it becomes more significant in event 'II'. This out-of-plane deformation is possibly due to local buckling of the spar cap in the dotted circle region and/or material failure at the adhesive joints connecting spar caps and the top shear web. Because no material damage is visible from the outside view, more evidence will be discussed based on strain measurements in the following sections to determine the cause.

\section{- Bebonding and crushing failure after the ultimate state}

A drastic drop of the load-carrying capacity is shown during the collapse process, which is much steeper than the progressive drop observed in the box beams loaded in the flapwise direction. This collapse process is of a brittle failure nature and the duration of event 'III' only lasts approximately $0.05 \mathrm{~s}$. The whitening region occurs throughout the flange width, indicating extensive adhesive debonding between the spar cap and the shear web. Moreover, the separated spar cap exhibits compressive crushing failure and visually apparent fiber breakage. 


\subsection{Post-collapse characteristics}

\subsubsection{Failure inspection after flapwise tests}

Post-collapse characteristics represent the final results of all failure modes and provide additional details on the possible root causes of collapse. The in-situ observation of CB_F2 is shown in Fig. 10 and Fig. 11, and that of CB_F3 is shown in Fig. 12. The crushing failure of shear webs leads to catastrophic composite failure, which includes matrix damage, fiber breakage and delamination in the facesheets. In particular, the magnified view in Fig. 11(e) shows that fibers in the $\pm 45^{\circ}$ laminates in the shear webs are peeled out from sandwich facesheets; such damage is probably caused by the tensile and shear stresses upon the outward deformation of the region. In addition, the compressive stress experienced in this region leads to fiber breakage with a rough and prickly fracture surface. After removing the loading plate, a pair of symmetrical failure regions is found near the contacting edges, as shown in Fig. 11(c), suggesting the transverse concave deformation experienced by the top spar cap during the loading.

Fig. 10 Post-collapse characteristics observed on the right side of CB_F2

Fig. 11 Post-collapse characteristics observed on the left side of CB_F2

The failure modes of the shear webs of CB_F3 are similar to those of CB_F2. Both box beams show adhesive cracks with an inclination angle between $15^{\circ}$ to $30^{\circ}$. These cracks occur at $120 \mathrm{~mm}$ 's span-wise locations and indicate substantial shear stresses in this region. Although the pre-delamination opens on the right side of $\mathrm{CB}_{-} \mathrm{F} 3$, it does not propagate during the loading. Instead, the debonding between the shear webs and the top spar cap originates from the existing adhesive cracks and propagates along the adhesive layers. The debonding also involves delamination of spar caps as can be seen from Figs. 12 (b) and (c) that some fibers from the spar cap laminates remain adhered to the adhesive layer.

Fig. 12 Post-collapse characteristics observed on CB_F3

\subsubsection{Failure inspection after edgewise tests}

The in-situ observation of CB_E1 and CB_E2 exhibits similar post-collapse characteristics, as shown in Fig. 13 and Fig. 14. From the right and left views, the primary failure region marked by the black dotted lines is consistent with the width of the flange originally adhered to the spar cap. In particular, the whitening region with longitudinal cracks in the magnified images of Fig. 13(b) and Fig. 14(b) shows matrix damage and fiber breakage in the spar caps driven by severe bulging deformation. Fig. 13(a) and Fig. 14(a) show only debonding at the right side, suggesting that debonding occurs prior to crushing failure.

The top views shown in Fig. 13(c) and Fig. 14(c) reveal large openings between the spar caps and the top shear web ranging from approximately 0 to $\pm 300 \mathrm{~mm}$ along the longitudinal direction. This separation is caused by both debonding and delamination of the spar caps. However, this delamination is an additional result of the debonding propagation and is less responsible for the beam collapse.

Fig. 13 Post-collapse characteristics observed on CB_E1

Fig. 14 Post-collapse characteristics observed on CB_E2

\subsection{Local strain response}

\subsubsection{Strain response under flapwise loading}

According to the previous observations, the main failure modes are the same in both CB_F2 and CB_F3 with little effects of predelamination. Strain response of CB_F2 is discussed here as representative. Although many strain gauges are placed on the outside 
surfaces of CB_F2, only the two locations (200 mm and $350 \mathrm{~mm}$ ) of most interest are discussed to explain nonlinear behavior, and the rest measurements will be used for comparison in the future numerical analysis. The local strains measured at the top spar cap of CB_F2 are shown in Fig. 15, where $\varepsilon_{11}$ and $\varepsilon_{22}$ denote the longitudinal and transverse strains, respectively.

Fig. 15 Local strain response on the top spar cap of CB_F2

It is known from the aforementioned discussion that the top spar cap underneath the loading plate at the mid-span is subject to concave deformation. As shown in Fig. 15(a), both $\varepsilon_{11}$ and $\varepsilon_{22}$ at $200 \mathrm{~mm}$ bend toward the positive strain regime with the increase of applied load before $P_{C F B 2}^{N}$. This nonlinearity indicates the spar cap at $200 \mathrm{~mm}$ undergoes bulging out, or convex deformation in both longitudinal and transverse directions. This deformation is of opposite direction of the deformation of the adjacent spar cap at the midspan. From the load level $P_{C F B 2}^{N}$, the longitudinal strain $\varepsilon_{11}$ at $200 \mathrm{~mm}$ increases dramatically while the transverse stain $\varepsilon_{22}$ reduces. These changes of stains indicate the spar cap, which is initially convex along both longitudinal and transverse directions, undergoes more convex deformation in the longitudinal direction but flattens a little bit in the transverse direction, suggesting material failure in the shear web and adhesive joints may occur and release boundary constraint of the spar cap. Nevertheless, the box beam continues to take the applied load to the peak with a noticeable nonlinearity showing in the global structural response in terms of applied load versus deflection.

Fig. 15(b) shows the strain response during the post-peak loading history from the ultimate load $P_{C F B 2}^{U}$ to the residual load $P_{C F B 2}^{R}$. From $P_{C F B 2}^{U}$ to the post-peak load $P_{C F B 2}^{X}$, both longitudinal and transverse strains at the outside surface of the top spar cap at $200 \mathrm{~mm}$ increase in the tensile strain regime. These strain measurements give direct evidence of significant bulging out, or convex deformation, of the top spar cap at this location. Considering the concave deformation of the top spar cap at the mid-span location, i.e., $0 \sim 40 \mathrm{~mm}$, as previously identified, one conclusion can be made that there must exist a location between 40 and 200 mm which experiences the maximum through-thickness tensile strain or maximum strain gradient (indicating maximum shear stress). This finding may be a key to explain the oblique adhesive cracks found near the $120 \mathrm{~mm}$ location. After $P_{C F B 2}^{X}$, the longitudinal strain decreases at $200 \mathrm{~mm}$ but increases at $350 \mathrm{~mm}$. This strain pattern shows that the location of maximum through-thickness tensile strain or maximum strain gradient moves toward the supported ends of the box beam, which is consistent with the observed propagation of debonding in adhesive joints.

\subsubsection{Strain response of pre-delamination}

Fig. 16 shows the longitudinal strains on the outside surface of the top spar cap at 350 and $500 \mathrm{~mm}$ locations with pre-delamination. All compressive strains respond to the applied load in a rather linear fashion before the ultimate load is reached. Dramatic changes of strains occur at two load levels, marked as $P_{Y}$ and $P_{d}$. At $P_{Y}$, the strains at only the middle and left sides of $350 \mathrm{~mm}$ increase in tension, indicating separation of the top spar cap from the shear web. This observation is in agreement with the debonding at 200 400 $\mathrm{mm}$ at the left side as shown in Fig. 8(d-i). At $P_{d}$, the strain at the right side of $350 \mathrm{~mm}$ shows an increase in tension due to separation between the Teflon film and the unidirectional ply. Moreover, compressive strain increases at $500 \mathrm{~mm}$, which is located at the border of the pre-delamination region. Therefore, it is known that debonding occurs prior to pre-delamination opening.

Fig. 16 Longitudinal strains on the pre-delamination region of the top spar cap of CB_F3

\subsubsection{Strain response under edgewise loading}

Figs. 17 (a) and (b) show the transverse strains along the height direction of the spar caps at the mid-span section under edgewise loading, where the strain gauges are located at $0.833 \mathrm{H}$ and $0.5 \mathrm{H}$, with $\mathrm{H}$ being the height of the box beam. Figs. 17 (c) and (d) show the strain response of the top and bottom shear webs, where the locations \#5, \#7/\#8 and \#6 are 0,80 and $200 \mathrm{~mm}$ away from mid-span section, respectively. 
The transverse compression strain at location \#2 shows a drastic increase toward the positive strain regime and decreases just before the ultimate load is reached. The increase in strain is due to spar cap buckling in the form of bulging out in two events 'I' and 'II'. However, the main driver of this process is adhesive cracking near location \#2, where the inside surface of the spar cap is originally adhered to the shear web. The strain decreases prior to the ultimate load indicates that the boundary constraint of the spar cap is released due to adhesive failure.

Before the occurrence of event ' $I$ ', all strains in the shear webs show linearity, possibly because the Brazier effect has little effect on the cross section as a result of the higher transverse stiffness of the shear web than spar cap when the box beam is loaded in edgewise direction. However, the nonlinear in-plane shear has significant influence on the shear deformation and further affects the buckling behavior of the spar caps. The tensile strains at locations \#1 and \#3 bend toward the positive strain regime, indicating spar caps are bulging out during the loading.

Fig. 17 Strain response before the ultimate load under edgewise loading

\section{Plausible failure mechanism}

Based on the aforementioned evidence, CB_F2 and CB_E2 are taken as representative examples to demonstrate the plausible failure mechanism of the composite box beams in Fig. 18 and Fig. 19. The sketches in the second column of the figures show conceptual deformations of the mid-span section and the red marks indicate material failure. For the flapwise loading, only the top spar cap primarily subject to compressive force during the loading is plotted in Fig. 18 to illustrate the failure response of the box beams.

- Local buckling in the form of bulging initiates at the compressive side of the shear web as shown in Fig. 18(a). This buckling is driven by compressive force due to the global beam bending, and it is also affected by the transverse concave deformation of the adjacent spar cap due to the Brazier effect. Load introduction affects the local deformation and buckling mode of the mid-span section.

- Local buckling of shear web increases with the applied load and leads to material failure in the facesheet of shear webs and/or adhesive joint as shown in Fig. 18(b). The material degradation in turn promotes the local buckling. Their interaction eventually drives the shear web to compressive crushing failure, as shown in Figs. 18 (c) and (d), resulting in the significant loss of loadcarrying capacity of the box beam.

- The buckling of the top spar cap is also developed and it becomes significant when the local material failure in shear webs and/or adhesive joint occurs. The buckling of spar cap induces large shear stress and through-thickness tensile stress at the $\pm 120 \mathrm{~mm}$ locations, which further result in oblique cracks in the adhesive joint, as shown in Fig. 18(c). The propagation of cracks leads to catastrophic debonding as shown in Fig. 18(e). Finally, the box beam retains a residual load-carrying capacity due to the intact bottom spar cap.

Fig. 18 Schematic illustration of failure mechanisms of CB_F2 under flapwise loading

For edgewise loading, particular focus is placed on the spar cap and the adhesive joint, both of which are primarily subjected to compression and shear, as shown in Fig. 19.

Shear nonlinearity of the unidirectional plies in spar caps contributes to nonlinear shear deformation, as shown in Fig. 19(a). This shear nonlinearity is significant enough to be reflected in the global load-displacement response of the box beam under three-point edgewise bending. During this loading process, spar caps bulge out resulting in significant stresses in adhesive joints, which exhibit cracks as shown in Fig. 19(b).

- The adhesive cracking releases local constraint adhered to the shear webs, leading to further local buckling of spar caps, as shown in Fig. 19(b). Local material damage progresses in the region between spar caps and shear webs, resulting in load fluctuation observed in the global load-displacement response, as shown in Fig. 19(c). 
- Local material failure and buckling of spar caps prompt the propagation of adhesive debonding and delamination, leading to crushing failure of the spar cap and a drastic load drop of the box beam as a result as shown in Figs. 19 (d) and (e).

Fig. 19 Schematic illustration of failure mechanisms of CB_E2 under edgewise loading

\section{Conclusions and future work}

In this work, experimental investigation was carried out to study structural collapse of load-carrying composite box beams typically used in wind turbine blades. The nonlinear behavior during the loading history of the box beams were examined thoroughly by taking into consideration the representative load conditions, i.e., flapwise and edgewise loading, and different spar cap configurations, i.e., thickness and pre-delamination. The following conclusions are drawn:

1) The ultimate strength of composite box beams is higher under edgewise loading than flapwise loading due to different controlling failure modes. For the flapwise loading, local buckling drives the shear webs to compressive crushing failure. For the edgewise loading, debonding and buckling of the spar cap is triggered by local adhesive cracking, with contribution from shear nonlinearity of unidirectional plies.

2) The Brazier effect influences local buckling differently depending on loading directions. Under flapwise loading, the Brazier effect leads to local buckling due to low transverse stiffness of the spar cap containing unidirectional plies. Under edgewise loading, shear webs with higher transverse stiffness can better resist the Brazier effect and constrain local buckling.

3) Although pre-delamination designed in the spar caps contributes to the failure process of the box beams, it has a negligible effect on the ultimate strength and post-collapse characteristics in this study. Instead, the buckling of the top spar cap is a dominant phenomenon which leads to debonding of adhesive joints between the spar cap and shear webs due to shear and through-thickness tensile stress.

4) Equations based on the sandwich beam theory are modified to estimate the pre-peak stiffness of composite box beams under three-point bending. The calculated results are in agreement with the results of the flapwise tests but not with edgewise tests, where shear nonlinearity of unidirectional plies in the spar caps has to be considered.

In this study, three-point bending setup introduces concentrated load and affects strength and failure of box beams. Failure behavior of the box beams may be different when they are under pure bending and combined bending and torsion. A three-dimensional solid element finite element model has been developed to further examine the effects of test setups, boundary conditions, more realistic airfoil geometries of load-carrying components used in wind turbine blades. The experimental results presented in this study provide valuable information for model development and validation, which will be presented in the future study.

\section{Author contributions}

Jing Tang prepared and performed the experiments, processed and analyzed the data and wrote the first version of this manuscript. Xiao Chen supervised the study, designed, prepared and performed the experiments, interpreted the data, wrote and revised the manuscript.

\section{Acknowledgments}

The authors are very grateful for experimental support provided by Wei Zhao, Zongjie Liu, Ruifang Cao and Yueshu Zhai. The authors acknowledge financial support from the National Natural Science Foundation of China (51405468). This study is also partially supported by the DARWIN Project (Drone Application for pioneering Reporting in Wind turbine blade Inspections) funded by Innovation Fund Denmark and the BLATIGUE project (Fast and Efficient Fatigue Test of Large Wind Turbine Blades) funded by the Energy Technology Development and Demonstration Program (EUDP). The authors would like to thank anonymous reviewers for their valuable suggestions and insightful comments that helped improve this work.

\section{References}


[1] Overgaard LCT, Lund E, Thomsen OT. Structural collapse of a wind turbine blade- Part A: static test and equivalent single layered models. Composites Part A 2010;41(2):257-270.

[2] Chen X, Zhao W, Zhao X, Xu JZ. Failure test and finite element simulation of a large wind turbine composite blade under static loading. Energies 2014;7(4):2274-2297.

[3] Chen X, Zhao W, Zhao XL, Xu JZ. Preliminary failure investigation of a 52.3m glass/epoxy composite wind turbine blade. Engineering Failure Analysis 2014;44(0):345-350.

[4] Chen X, Qin ZW, Yang K, Zhao XL, Xu JZ. Numerical analysis and experimental investigation of wind turbine blades with innovative features: structural response and characteristics. Science China Technological Sciences 2015;58(1):1-8.

[5] Chen X. Collapse of a 47-meter composite blade under combined bending and torsion in a full-scale static test. $35^{\text {th }}$ AIAA SciTech Wind Energy Symposium, TX, USA: 09-13 January 2017.

[6] Chen X, Experimental investigation on structural collapse of a large composite wind turbine blade under combined bending and torsion. Composite Structures 2017;160:435-445.

[7] DNV GL Standard, DNVGL-ST-0376, Rotor blades for wind turbines, DNV GL; Edition December 2015.

[8] Jensen FM, Falzon BG, Ankersen J, Stang H. Structural testing and numerical simulation of a $34 \mathrm{~m}$ composite wind turbine blade. Composite Structures 2006;76:52-61.

[9] Jensen FM, Branner K, Nielsen PH, Berring P. Full scale test of a SSP 34m box girder 1- data report. Ris $\varnothing-\mathrm{R}-1622(\mathrm{EN})$, Ris $\varnothing$ National Laboratory; 2008, ISBN: 978-87-550-3636-9, ISSN: 0106-2840.

[10] Jensen FM, Branner K, Nielsen PH, Berring P. Full scale test of a SSP 34m box girder 2- data report. Ris $\varnothing-\mathrm{R}-1588(\mathrm{EN})$, Ris $\varnothing$ National Laboratory; 2008, ISBN: 978-87550-3574-4, ISSN: 0106-2840.

[11] Yang JS, Peng CY, Xiao JY, Zeng JC, Xing SL, Jin JT, Deng H. Structural investigation of composite wind turbine blade considering structural collapse in full-scale static tests. Composite Structures 2013;3:15-29.

[12] Chen X, Zhao XL, Xu JZ. Revisiting the structural collapse of a 52.3 composite wind turbine blade in a full-scale bending test. Wind Energy 2017;20(6):1111-1127.

[13] Couturier PJ, Krenk S. Nonlinear collapse of general thin-walled cross-sections under pure bending. AIAA Journal 2016;54(12):1-9.

[14] Vo TP, Lee J. Geometrically nonlinear analysis of thin-walled composite box beams. Computers and Structures 2009;87(3):236245.

[15] Estep DD, GangaRao HVS, Dittenber DB, Qureshi MA. Response of pultruded glass composite box beams under bending and shear. Composites Part B. 2016;88:150-161.

[16] Cole B, Miyase A, Yu TP, Lo KH, Wang SS. Failure modes and strength of composite box beam structures. Proceeding of the American Society for Composites $30^{\text {th }}$ Annual Technical Conference; 2015.

[17] Yu TP, Miyase A, Lo KH, Wang SS. Composite box-beam failure modes and strength: 3D modeling and analysis and comparison with experimental results. Proceeding of the American Society for Composites $31^{\text {th }}$ Annual Technical Conference; 2016.

[18] International Electrical Commission, IEC Standard 61400-23 Wind turbines generator systems - Part 23: Full-scale structural testing of rotor blades, IEC; Edition April 2014.

[19] Chen X, Li CF, Tang J. Structural integrity of wind turbines impacted by tropical cyclones: A case study from China. Journal of Physics: Conference Series 2016; 753.

[20] Chen X, Li CF, Xu JZ. Failure investigation on a coastal wind farm damaged by super typhoon: A forensic engineering study. Journal of Wind Engineering and Industrial Aerodynamics 2015;147:132-142.

[21] Chen X, Xu JZ. Structural failure analysis of wind turbines impacted by super typhoon Usagi. Engineering Failure Analysis 2016; 60:391-404.

[22] Chang FK, Lessard LB. Damage tolerance of laminated composites containing an open hole and subjected to compressive loadings- Part I: analysis. Journal of Composite Materials 1991; 25.

[23] Steeves CA, Fleck NA. Collapse mechanisms of sandwich beams with composite faces and a foam core, loaded in three-point 
bending- Part II: experimental investigation and numerical modelling. International Journal of Mechanical Sciences 2004; 46(4):585-608.

[24] Gdoutos EE, Daniel IM. Nonlinear stress and deformation behaviour of composite sandwich beams. Applied Mechanics and Materials 2008;13-14:91-98. 